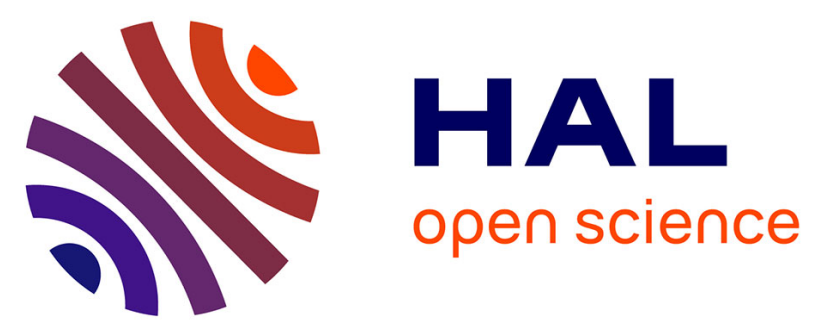

\title{
Cubic Sr_2ScGaO_5 perovskite: structural stability, oxygen defect structure, and ion conductivity explored on single crystals
}

Serena Corallini, Monica Ceretti, Alain Cousson, Clemens Ritter, Marco Longhin, Philippe Papet, Werner Paulus

\section{To cite this version:}

Serena Corallini, Monica Ceretti, Alain Cousson, Clemens Ritter, Marco Longhin, et al.. Cubic Sr_2ScGaO_5 perovskite: structural stability, oxygen defect structure, and ion conductivity explored on single crystals. Inorganic Chemistry, 2017, 56 (5), pp.2977-2984. 10.1021/acs.inorgchem.6b03106 . hal-01492549

\section{HAL Id: hal-01492549 \\ https://hal.science/hal-01492549}

Submitted on 27 Oct 2021

HAL is a multi-disciplinary open access archive for the deposit and dissemination of scientific research documents, whether they are published or not. The documents may come from teaching and research institutions in France or abroad, or from public or private research centers.
L'archive ouverte pluridisciplinaire HAL, est destinée au dépôt et à la diffusion de documents scientifiques de niveau recherche, publiés ou non, émanant des établissements d'enseignement et de recherche français ou étrangers, des laboratoires publics ou privés. 


\section{Cubic $\mathrm{Sr}_{2} \mathrm{ScGaO}_{5}$ perovskite: structural stability,}

\section{oxygen defect structure and ion conductivity}

\section{explored on single crystals}

Serena Corallini ${ }^{a}$, Monica Ceretti ${ }^{a,},{ }^{*}$, Alain Cousson ${ }^{b}$, Clemens Ritter $^{c}$, Marco Longhin $^{a}$, Philippe Papet $^{a}$ and Werner Paulus ${ }^{a}$

a. Institut Charles Gerhardt, UMR 5253 CNRS Université Montpellier, C2M, P1 Eugene Bataillon, 34095 Montpellier, France.

b. Laboratoire Léon Brillouin, UMR12, CEA-CNRS, CEA Saclay, 91191 Gif Sur Yvette, France

c. Institut Laue Langevin, Grenoble, France 
ABSTRACT. Oxygen deficient $\mathrm{Sr}_{2} \mathrm{ScGaO}_{5}$ single-crystals with cubic perovskite structure were grown by the floating-zone technique. The transparent crystals of this pure 3D oxygen electrolyte are metastable at ambient temperature, showing $1 / 6$ of all oxygen positions vacant. While neutron single crystal diffraction, followed by Maximum Entropy analysis, revealed a strong anharmonic displacements for the oxygen atoms, a predominant formation of $\mathrm{ScO}_{6}$ octahedra and $\mathrm{GaO}_{4}$ tetrahedra is indicated by Raman spectroscopic studies, resulting in a complex oxygen defect structure with short range order. Temperature dependent X-ray diffraction powder diffraction (XPD) and neutron powder diffraction (NPD) studies reveal the cubic $\mathrm{Sr}_{2} \mathrm{ScGaO}_{5}$ to be thermodynamically stable only above $1400^{\circ} \mathrm{C}$, while the stable modification below this temperature shows the brownmillerite framework with orthorhombic symmetry. Cubic $\mathrm{Sr}_{2} \mathrm{ScGaO}_{5}$ remains surprisingly kinematically stable upon heating from ambient to $1300^{\circ} \mathrm{C}$, indicating a huge inertia for the retransformation towards the thermodynamically stable brownmillerite phase. Ionic conductivity investigated by impedance spectroscopy was found to be $10^{-4} \mathrm{~S} / \mathrm{cm}$ at $600^{\circ} \mathrm{C}$, while oxygen ${ }^{18} \mathrm{O} /{ }^{16} \mathrm{O}$ isotope exchange indicates a free oxygen mobility to set in at around $500^{\circ} \mathrm{C}$.

KEYWORDS. Oxygen deficient perovskite, single crystal growth, oxygen ionic conduction, neutron diffraction. 


\section{Introduction}

Oxygen ion conductors operating at moderate temperatures are materials of major interest for a series of application in the area of solid state ionics (Solid Oxide Fuel Cells (SOFC), batteries, electrodes, sensors, catalysts). ${ }^{1,2}$ Still today high operating temperatures above $800^{\circ} \mathrm{C}$ are generally required to obtain reasonable efficiency, limiting their application. In the search for improved oxygen ion conductors, oxygen deficient perovskite structures play an important role. In this context, oxides with perovskite-type structure have been widely investigated, $(\mathrm{Sr}, \mathrm{Mg})$ doped lanthanum gallate $\mathrm{LaGaO}_{3}$ being one prominent example as intermediate temperature electrolyte, with promising performance..$^{3-7}$ As a consequence of the formation of protonic defects generated by a reaction between oxygen defects and water vapor, oxygen deficient perovskites are also potential candidates for proton conduction.

In this respect oxides with brownmillerite type structure $\left(\mathrm{A}_{2} \mathrm{BB}^{\prime} \mathrm{O}_{5}\right)$, have attracted much attention, especially as they show oxygen ion mobility down to ambient temperature. ${ }^{8-12}$ This unusual low-temperature oxygen mobility has been evidenced to rely on a phonon assisted diffusion mechanism, essentially based on large, dynamically activated displacements of the apical oxygen atoms of the $\mathrm{BO}_{6}$ octahedra. ${ }^{13}$ Oxygen diffusion at room temperature thus makes this class of compounds attractive for many technologically important applications in the field of solid state electrolytes and more specifically for membranes and pure electrolytes.

Brownmillerite type frameworks containing B-cations with saturated or empty electron shells, such as $d^{0}$ or $d^{10}$ configurations, present a special case, as they impose a fixed oxygen stoichiometry, avoiding complications such as structural transitions related to oxygen uptake or release. This makes them good candidates to learn more about the oxygen diffusion mechanisms 
on a microscopic level, as no change in the valence state of the B-cations nor their polyhedral arrangement is supposed to occur. In this context, cation substituted $\mathrm{Ba}_{2} \operatorname{In}_{2} \mathrm{O}_{5}$ is one of the most studied brownmillerite type electrolytes for SOFC applications. ${ }^{4,14}$

Recently, $\mathrm{Sr}_{2} \mathrm{ScGaO}_{5}$ has been reported as a new brownmillerite phase, showing B-cation ordering of $\mathrm{Sc}^{3+}$ and $\mathrm{Ga}^{3+}$ on octahedral and tetrahedral sites respectively, adopting the $I 2 \mathrm{mb}$ space-group at ambient temperature. ${ }^{15-16}$ This symmetry implies an ordered arrangement of the $\left(\mathrm{GaO}_{4}\right)_{\infty}$-tetrahedral chains, which may explain accordingly the absence of oxygen diffusion close to ambient. Combining NPD and synchrotron diffraction together with oxygen isotope ${ }^{18} \mathrm{O} /{ }^{16} \mathrm{O}$ exchange experiments, the onset of oxygen mobility was found to occur at $500^{\circ} \mathrm{C}$, which has been interpreted as originating from a subtle phase transition from $I 2 m b$ towards Imma, and from concurrent changes in the lattice dynamics, promoting a dynamic and coherent switching of the infinite $\left(\mathrm{GaO}_{4}\right)_{\infty}$-chains. ${ }^{16}$

In addition, brownmillerite $\mathrm{Sr}_{2} \mathrm{ScGaO}_{5}$ shows a phase transition to the cubic perovskite structure above $1500^{\circ} \mathrm{C}$, associated with improved oxygen ion conduction, probably related to the $3 \mathrm{D}$ perovskite framework and associated diffusion pathways. ${ }^{17}$ Since the cubic symmetry can be easily maintained down to ambient temperature via simple furnace cooling, SSGO turns out to be a model system to investigate the influence of the structural dimensionality of the underlying framework for oxygen diffusion mechanisms.

We report here on a combination of characterization on the cubic $\mathrm{Sr}_{2} \mathrm{ScGaO}_{5}$ single crystal (in the following indicated as c-SSGO).

All the studies so far reported on such material were performed on polycrystalline samples. Our effort to dispose large and high quality crystals of $\mathrm{Sr}_{2} \mathrm{ScGaO}_{5}$ goes along with our 
motivation to study anisotropic oxygen mobility together with accurate structural analysis and lattice dynamics with inelastic neutron scattering. It is also a rare case where single crystals can be obtained for cubic and stoichiometric oxygen deficient perovskite, suitable for high resolution X-ray and neutron diffraction studies. High-resolution structure analysis has been performed combining X-rays and neutron diffraction methods. Single crystal neutron diffraction with subsequent analysis of the nuclear scattering density by the Maximum Entropy Method has been performed in order to describe in more detail oxygen displacement factors and associated diffusion pathways.

To better understand the oxygen mobility mechanisms, these studies were complemented by Raman and impedance spectroscopy as well as by the determination of the oxygen isotope exchange behaviour via thermogravimetric analysis coupled mass spectroscopy studies on ${ }^{18} \mathrm{O}$ enriched c-SSG ${ }^{18} \mathrm{O}$, in ${ }^{16} \mathrm{O}_{2}$ atmosphere.

\section{Experimental}

\section{Single crystal growth}

Polycrystalline $\mathrm{Sr}_{2} \mathrm{ScGaO}_{5}$ with brownmillerite structure was prepared using standard solidstate chemistry synthesis at high temperature. High purity $\mathrm{SrCO}_{3}(99,995 \%, \mathrm{ALDRICH}), \mathrm{Ga}_{2} \mathrm{O}_{3}$ $(99,99 \%, \mathrm{ALDRICH})$ and $\mathrm{Sc}_{2} \mathrm{O}_{3}$ (REacton 99,99\% REO, ALFA AESAR) were thoroughly mixed and heated in air at $1200^{\circ} \mathrm{C}$ for $48 \mathrm{~h}$. Seed and feed rods for crystal growth were obtained by hydrostatic pressing the obtained $\mathrm{Sr}_{2} \mathrm{ScGaO}_{5}$ powder at 10 bars in a cylindrical latex tube of 6 $\mathrm{mm}$ in diameter and $100 \mathrm{~mm}$ in length. The as obtained rods were then sintered in air at $1200^{\circ} \mathrm{C}$ for $24 \mathrm{~h}$ to obtain dense polycrystalline rods. Large high quality c-SSGO single crystals have been obtained and characterised as reported elsewhere. ${ }^{17}$ Single-crystal growth was carried out 
by the floating zone method using a mirror furnace (NEC SC2, Japan) equipped with two $500 \mathrm{~W}$ halogen lamps as heat source and two ellipsoidal mirrors. Crystal growth was performed in air with a typical traveling rate of $2 \mathrm{~mm} / \mathrm{h}$, while the upper and lower shafts were rotated in opposite directions at $25 \mathrm{rpm}$.

\section{Structural analysis}

Several characterizations were performed on the as grown $\mathrm{Sr}_{2} \mathrm{ScGaO}_{5}$ single crystals. Phase purity and structure were checked by laboratory X-ray powder diffraction on a Bruker AXS D8 Advance diffractometer using $\mathrm{Cu} K_{a l}$ radiation. T-dependent X-ray powder patterns up to $1600^{\circ} \mathrm{C}$ were collected on a Panalytical Empyrean diffractometer $\left(\mathrm{Cu} \mathrm{K}_{\alpha 1,2}\right)$, equipped with the HTK $16 \mathrm{~N}$ Anton Parr high temperature chamber.

Neutron diffraction on the as obtained single crystals have been performed on the $5 \mathrm{C} 2$ single diffractometer installed at the LLB (ORPHEE reactor in Saclay, France) with $\lambda=0.83 \AA$. Such short wavelength allows having an excellent data quality up to high momentum transfer of 0.72 $\AA^{-1}$, in order to better explore anisotropic and anharmonic displacement parameters. No absorption correction has been applied due to the negligible absorption coefficients.

Complementary T-dependent NPD patterns were obtained on the high-resolution diffractometer D2B $(\lambda=1.59 \AA)$, at the high-flux reactor of the Laue-Langevin Institute (ILL, France). Single crystal structure refinements were carried out using Shelx $1^{18}$, while the powder diffraction data were analyzed by the Rietveld method ${ }^{19}$ using the FullProf suite software ${ }^{20}$. Nuclear densities were reconstructed in real space through the Maximum Entropy Method (MEM) via PRIMA (Practice Iterative MEM Analysis), ${ }^{21}$ scattering lengths were taken from ref. ${ }^{22}$. Nuclear density distributions were visualized by using the VESTA program. ${ }^{23}$ 
The elemental composition and homogeneity were checked by Scanning Electron Microscopy (SEM) analysis using a JEOL JSM 6400 microscope, equipped with an OXFORD INCA EDS instrument for atomic recognition via X-ray fluorescence spectroscopy. SEM/EDS analyses have been performed on a cross section ( $4 \mathrm{~mm}$ in diameter) of the grown crystal, sliced perpendicular to the growth direction.

\section{Raman Spectroscopy}

Raman spectra were recorded in air by using a backscattering micro-Raman spectrometer LabRAM ARAMIS IR2 (Horiba Jobin Yvon) with helium-neon laser (633 nm) excitation.

\section{Impedance spectroscopy}

Ionic conductivity of the as grown SSGO was measured by alternating current (AC) impedance spectroscopy (Solartron 1260 Impedance Analyzer). The single crystal was cut into disks coated with a Pt paste on both sides and pressed in two Pt disks to ensure bonding. The experiments were carried out at different temperatures $\left(300^{\circ} \mathrm{C}, 400^{\circ} \mathrm{C}, 500^{\circ} \mathrm{C}\right.$ and $\left.600^{\circ} \mathrm{C}\right)$ in air at an applied voltage of $0.1 \mathrm{~V}$ in the frequency range from $0.1 \mathrm{~Hz}$ to $1 \mathrm{MHz}$. Equivalent circuit modelling was performed by using ZView (Scribner Associates)

\section{Isotope exchange}

Polycrystalline SSGO, obtained by crushing a small part of the single crystal, has been characterized by isotopic exchange ${ }^{18} \mathrm{O} /{ }^{16} \mathrm{O}$ and Thermogravimetric Analysis (TGA) coupled with MS. Thermogravimetric measurements were carried out on a NETSCH thermobalance Jupiter STA 449C, equipped with a PFEIFFER VACUUM Thermo Star mass spectrometer. 


\section{Results and Discussion}

When synthesizing polycrystalline $\mathrm{Sr}_{2} \mathrm{ScGaO}_{5}$ at $1200^{\circ} \mathrm{C}$ by classical solid state reaction, the brownmillerite modification is obtained, adopting at ambient the $I 2 \mathrm{mb}$ space group with unit cell parameters $a=5.91048(5) \AA, b=15.1594(1) \AA$ and $c=5.70926(4) \AA^{16}$. Heating to $1600^{\circ} \mathrm{C}$ leads, however, to the formation of the cubic perovskite structure, which is easily preserved when cooling down to ambient. ${ }^{17}$ The cubic perovskite phase is also obtained under single crystal growth conditions using the floating zone method reported above.

Chemical composition as well as its homogeneity were verified on a section cut from the as grown c-SSGO crystal. It was found that the atomic percentage of scandium, gallium, and strontium remains constant over the whole cross section, while the $\mathrm{Ga} / \mathrm{Sc}$ ratio was found to be 1 throughout the whole cross-section (see S3), in agreement with the chemical formula of $\mathrm{Sr}_{2} \mathrm{ScGaO}_{5}$. Phase purity of the grown single crystals was checked by X-ray powder diffraction on small sections of the as grown single crystals that were crushed into powder and used for all powder diffraction experiments reported below. XRD patterns of cubic SSGO (Figure 1) could be indexed with a cubic perovskite cell. No extra reflections are detectable, showing the high purity of the single crystal.

\section{Structure analysis by neutron and $\mathrm{X}$-ray diffraction}

Structure refinement has been done by a combination of X-ray and neutron diffraction experiments. In particular, considering the difference between the neutron scattering length $b$ of scandium (12.29 fm) and gallium (7.29 fm), neutron diffraction data were used to determine the overall B-cation and oxygen occupancies $(b=5.80 \mathrm{fm})$. 
Structure refinements from NPD data, using the Fullprof software ${ }^{24}$, yielded for polycrystalline c-SSGO an oxygen vacancy perovskite structure with space group $P m \overline{3} m$ and $a=3.9932(1) \AA$, corresponding to a unit cell volume of $63.6736(9) \AA^{3}$ (Figure 1 and Table 1 ). Contrary to orthorhombic $\mathrm{Sr}_{2} \mathrm{ScGaO}_{5}$, with gallium exclusively on tetrahedral and scandium on octahedral sites, c-SSGO implies, from a pure crystallographic point of view, an average $(\mathrm{Sc} / \mathrm{Ga})$ distribution on the B-site and accordingly a statistical distribution of the 1/6 oxygen vacancies. However, despite this average structural description, one might not exclude the existence of possible short range ordering, especially related to the formation of $\mathrm{GaO}_{4}$-tetrahedra beside $\mathrm{ScO}_{6}$-octahedra. This could then be equivalent to the formation of small differently oriented micro domains of the brownmillerite phase, as already reported for polycrystalline $\mathrm{Sr}_{2} \mathrm{Ga}_{1.5} \mathrm{Sc}_{0.5} \mathrm{O}_{5}$ and $\mathrm{Sr}_{2} \mathrm{Co}_{2-\mathrm{x}} \mathrm{AlxO}_{5 .}{ }^{15,25}$ Such a scenario can be expected in view of the rigid character and stability of both polytypes of polyhedra and would imply consequences for related oxygen diffusion pathways and energies. 


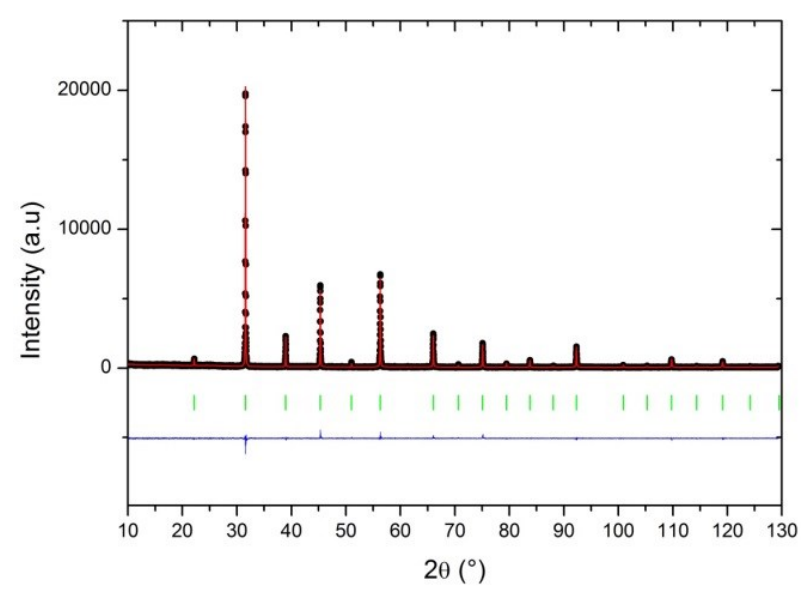

Figure 1: Rietveld refinement on the X-Ray powder diffraction data $\left(\mathrm{Cu} \mathrm{K}_{\alpha 1}\right)$ at $\mathrm{RT}$ of the ground single-crystal $\left(\mathrm{R}_{\mathrm{Bragg}}=4.44 \%, \chi 2=3.16, \mathrm{R}_{\mathrm{p}}=8.39 \%, \mathrm{R}_{\mathrm{pw}}=11.7 \%\right)$.

Figure 2 depicts powder X-ray diffraction patterns from room temperature up to $1600^{\circ} \mathrm{C}$, obtained during a heating cycle. Once obtained at ambient temperature, cubic SSGO shows a remarkable stability up to high temperatures. Orthorhombic $\mathrm{Sr}_{2} \mathrm{ScGaO}_{5}$ is re-obtained only above $1400^{\circ} \mathrm{C}$, while we noticed that a quantitative cubic to orthorhombic transformation proceeds on a timescale of several hours only. The pure cubic phase forms again on further heating to $1600^{\circ} \mathrm{C}$. Following these order-disorder transitions of SSGO, it becomes obvious that the cubic perovskite structure is kinetically stabilized during cooling but it is the thermodynamically stable phase at $1600^{\circ} \mathrm{C}$. At ambient temperature, the cubic phase is thus metastable, while the orthorhombic SSGO is the thermodynamically stable one. The kinetics of the observed phase transformations is somehow contrary to what is observed for other brownmillerite phases. $\mathrm{Sr}(\mathrm{Fe} / \mathrm{Co}) \mathrm{O}_{2.5}$, show for example a very rapid transformation from the oxygen deficient cubic perovskite phase at high temperature towards the brownmillerite framework, even when quenching in liquid $\mathrm{N}_{2} .^{11,26}$ While Fe and Co can easily adapts rapid changes in the coordination from octahedral to 
pyramidal and tetrahedral, no such correspondence exists either for $\mathrm{GaO}_{4}$-tetrahedra or for $\mathrm{ScO}_{6^{-}}$ octahedra having a more "rigid" character and also showing a "fixed" trivalent oxidation state for both spherical $3 d$ metal atoms.
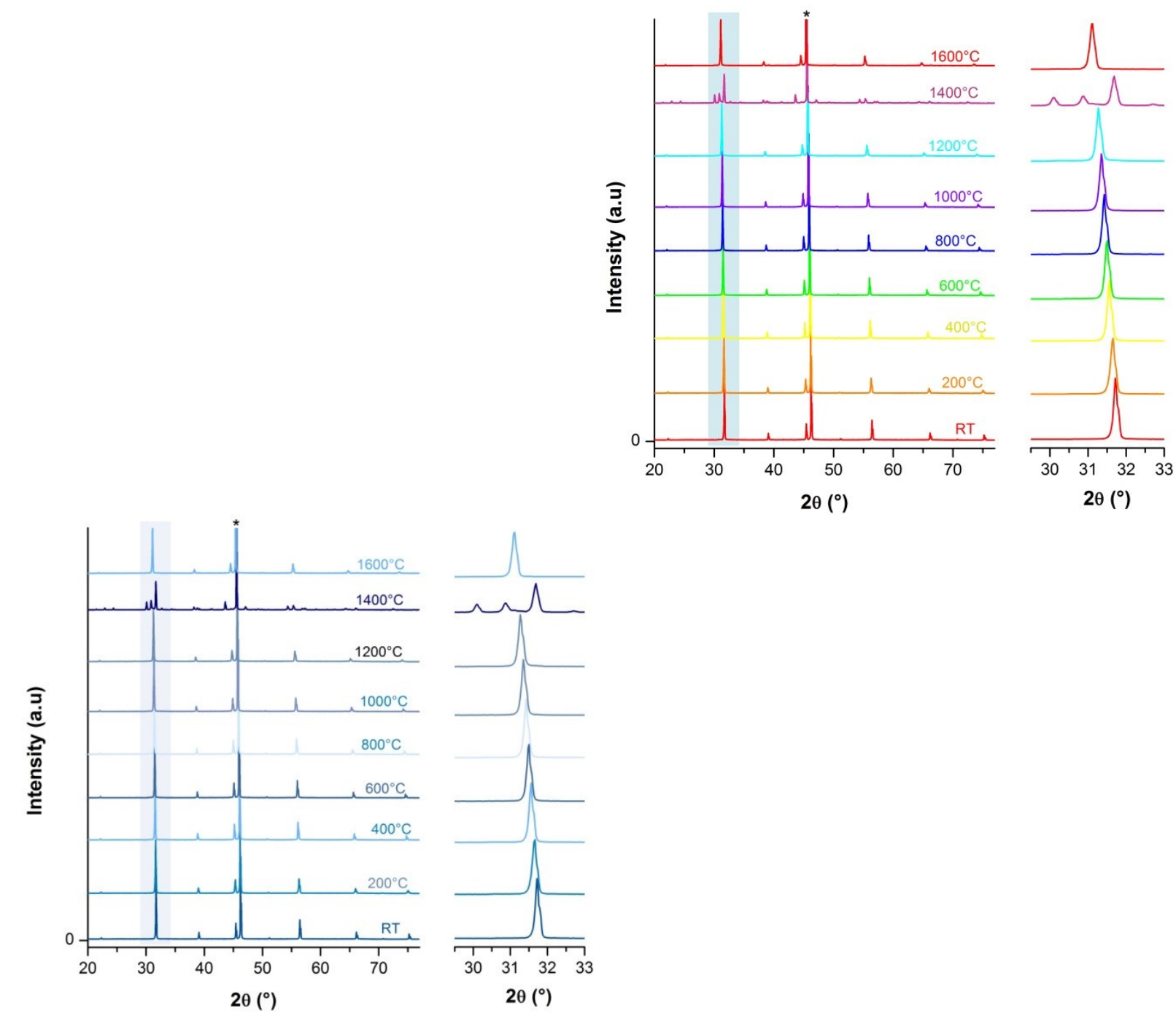

Figure 2: X-rays diffraction as a function of the temperature. On the right, zoom of a particular $2 \theta$ region where the formation of the brownmillerite phase is evident at $1400^{\circ} \mathrm{C}$. The very intense reflection marked with a star at $2 \theta=46.2^{\circ}$ originates from the Pt sample holder. 
We studied the structure of c-SSGO by single crystal neutron diffraction at room temperature, while X-ray and neutron powder diffraction studies have been done as a function of the temperature. Again, the polycrystalline samples have been obtained by crushing a c-SSGO single crystal. Results of the T-dependent structure refinements of the c-SSGO phase up to $1000^{\circ} \mathrm{C}$, obtained from NPD by the Rietveld method, are presented in Table 1 (the corresponding diffraction patterns are shown in the supplementary part S4). For all refinements, the $\mathrm{Sr}$ occupancy has been fixed to unity, while oxygen site occupancies were refined. The B-cation site occupancy was constrained to be unity, inversely correlating Ga and Sc contributions. The deviation from an equal $\mathrm{Sc} / \mathrm{Ga}$ occupation on the B-cation site was found to be less than $2 \%$, the same error bar holds for the oxygen occupancies, which are statistically vacant by $1 / 6$. Temperature variation of the unit cell parameter $a$ is linear over the whole temperature range (Figure 3a), revealing that the compound is stable and not subject to water release as at discontinuous trend was observed in water containing polycrystalline $\mathrm{Sr}_{2} \mathrm{Gat}_{1.5} \mathrm{Se}_{0.5} \Theta_{5 .}{ }^{15}$ Also neutron powder diffraction patterns showed a constant and low background which reveals unchanged with temperature, thus confirming the absence of water even at room temperature (Supplementary Info S3). It is better to mention that the sample was upheld without precautions in the air and water absorption has been reported to be the first step of the decomposition of similar compound (ref). .

Strongly anisotropic oxygen displacement factors become evident, giving rise to a disc shape distribution of all oxygen atoms as shown in Figure 4 (on the top). The $U_{22}\left(U_{33}\right)$ values (Figure 3b) do not converge towards zero with decreasing temperature, indicating that some significant static displacements persist at low temperatures. We underline a very good agreement between 
the ADP obtained by single crystal (2) and powder data (table 1), indicating small systematic errors derived from powder data
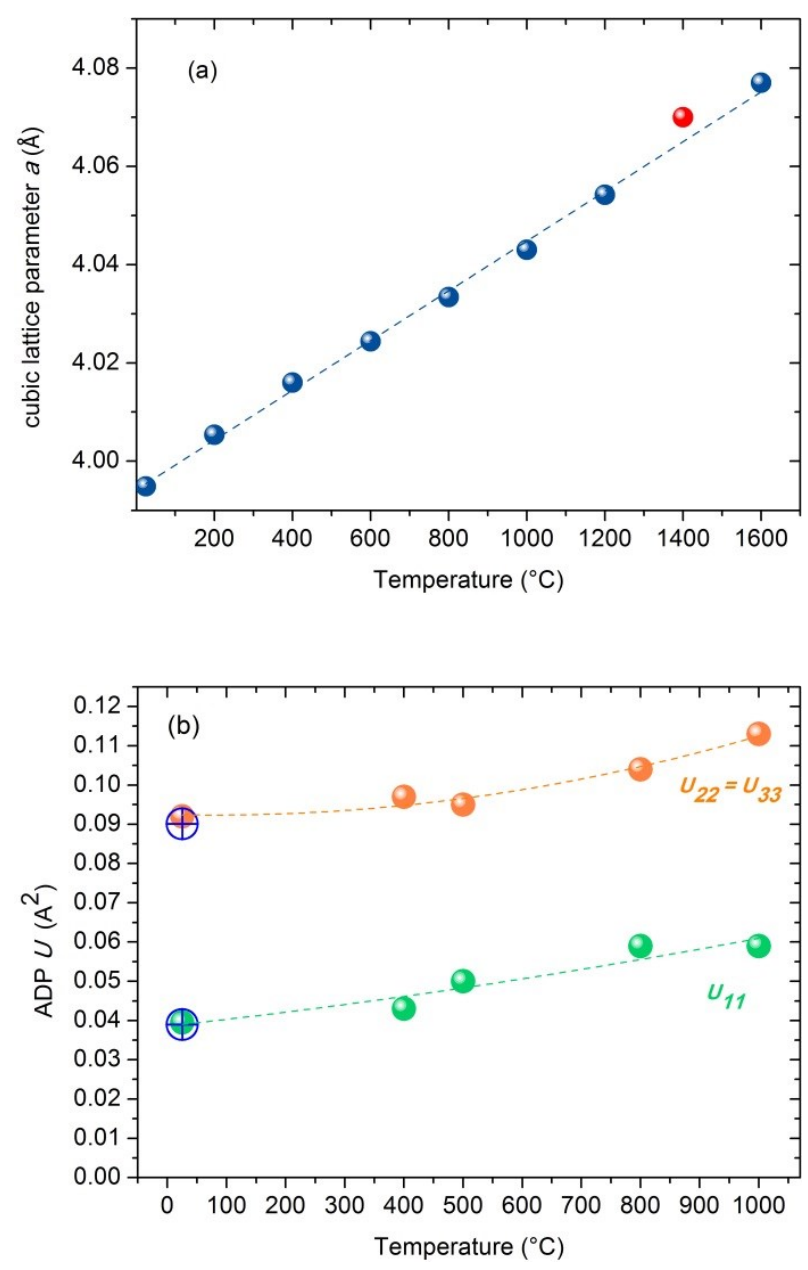
Figure 3: (a) Variation of the cubic lattice parameter $a$ as a function of the temperature for cSSGO. The red point presents the "average" brownmillerite lattice parameter, reduced to the cubic phase. (b) Evolution of the oxygen anisotropic displacement parameter $U_{\mathrm{ij}}$ (lines are only guide for the eyes), as a function of the temperature. All error bars are smaller than the symbol size. Open blue circles refer to oxygen anisotropic displacement determined by single crystal neutron diffraction, indicating a very good agreement between single crystal and powder data.

Table 1: Structural parameters after Rietveld refinements of NPD data obtained for crushed c-SSGO crystal at different temperatures. Diffraction data have been obtained on the high resolution powder diffractometer D2B at the ILL $(\lambda=1.59 \AA)$

\begin{tabular}{llllll}
\hline \hline & $\mathrm{T}=25^{\circ} \mathrm{C}$ & $\mathrm{T}=400^{\circ} \mathrm{C}$ & $\mathrm{T}=500^{\circ} \mathrm{C}$ & $\mathrm{T}=800^{\circ} \mathrm{C}$ & $\mathrm{T}=1000^{\circ} \mathrm{C}$ \\
\hline$a=b=c(\AA)$ & $3.9932(1)$ & $4.0101(1)$ & $4.0148(1)$ & $4.0303(1)$ & $4.0412(1)$ \\
$\mathrm{Vol}\left(\AA^{3}\right)$ & $63.6774(9)$ & $64.4877(10)$ & $64.7144(10)$ & $65.4661(13)$ & $65.9995(12)$ \\
$\mathrm{R}_{\mathrm{Bragg}}(\%)$ & 4.6 & 3.1 & 5.2 & 4.1 & 4.9 \\
$\mathrm{R}_{\text {wp }}(\%)$ & 6.6 & 6.1 & 6.3 & 6.4 & 5.9 \\
$\mathrm{R}_{\mathrm{p}}(\%)$ & 4.9 & 4.8 & 4.8 & 4.8 & 4.4 \\
$\chi^{2}$ & 2.8 & 2.1 & 2.1 & 1.9 & 2.7 \\
$\mathrm{Sr} \mathrm{U}_{\text {iso }}\left(\AA^{2}\right)$ & $0.0267(7)$ & $0.0361(8)$ & $0.0359(8)$ & $0.0444(9)$ & $0.0490(10)$ \\
$\mathrm{Sc} \mathrm{U}_{\text {iso }}\left(\AA^{2}\right)$ & $0.0280(6)$ & $0.0323(6)$ & $0.0338(6)$ & $0.0397(7)$ & $0.0437(8)$ \\
$\mathrm{Ga} \mathrm{U}_{\text {iso }}\left(\AA^{2}\right)$ & $0.0280(6)$ & $0.0323(6)$ & $0.0338(6)$ & $0.0397(7)$ & $0.0437(8)$ \\
$\mathrm{O} \quad \mathrm{U}_{11}\left(\AA^{2}\right)$ & $0.0398(2)$ & $0.042(2)$ & $0.050(2)$ & $0.059(2)$ & $0.059(3)$ \\
$\quad \mathrm{U}_{22}=\mathrm{U}_{33}\left(\AA^{2}\right)$ & $0.092(2)$ & $0.097(2)$ & $0.0945(18)$ & $0.104(2)$ & $0.113(3)$ \\
\hline
\end{tabular}




\begin{tabular}{clllll}
$\mathrm{U}_{\text {eq }}\left(\AA^{2}\right)$ & $0.0772(18)$ & $0.0823(19)$ & $0.0797(19)$ & $0.089(2)$ & $0.095(3)$ \\
O occ & $2.458(26)$ & $2.446(26)$ & $2.433(27)$ & $2.421(29)$ & $2.431(27)$ \\
\hline
\end{tabular}

In order to get a better insight, especially into the oxygen displacements, we investigated the respective scattering densities by high-resolution single crystal neutron diffraction up to high momentum transfers, and subsequent analysis of the nuclear densities by the Maximum Entropy Reconstruction. In this approach, the only structural constraint is imposed by the space group, and thus the resulting displacements are equivalent to an anharmonic description of the scattering densities. Values from a classical structure refinement obtained with SHELXL are similar to what has been obtained from NPD at ambient temperature (see Table 2). The scattering densities obtained from Maximum Entropy analysis (Figure 4, on the bottom) reveal, however, a more complex behaviour of the oxygen displacements, becoming cylindrically shaped with complex deepening. This directly reflects a possible presence of local distortions when considering $\mathrm{GaO}_{4-}$ tetrahedra and respective $\mathrm{ScO}_{6}$-octahedra. The values for both, $\mathrm{Sr}$ and $(\mathrm{Sc} / \mathrm{Ga})$-displacements, remain, however, comparable to the Debye-Waller factors found from the classical refinements given in Tables 1 and 2. Interestingly the anisotropic displacement factors found for c-SSGO are 
almost identical to what has been found for the homologous high temperature perovskite $\mathrm{Ba}_{2} \mathrm{In}_{2} \mathrm{O}_{5}$ at $980^{\circ} \mathrm{C}^{27}$ Such strong displacements could therefore be expected to be more generally present in oxygen deficient perovskite, and has to be taken into account, especially when describing the distribution of protonic defects around oxygen positions. For the proton conducting perovskite $\mathrm{BaZr}_{1 / 2} \operatorname{In}_{1 / 2} \mathrm{O}_{2.5}(\mathrm{OD})_{1 / 2}$ where, however, all oxygen sites are completely filled still one third of the displacement factors found for the high temperature modification of $\mathrm{Ba}_{2} \mathrm{In}_{2} \mathrm{O}_{5}$ are reported. ${ }^{28}$ For c-SSGO, the large displacements are supposed to result from distortions of the different $(\mathrm{Ga} / \mathrm{Sc}) \mathrm{O}_{\mathrm{x}}$ polyhedra, since a strongly developed lattice dynamics is unlikely to be present at ambient.

Table 2: $\mathrm{Sr}_{2} \mathrm{ScGaO}_{5}$ structure data obtained from single crystal neutron diffraction data, collected on diffractometer 5C2@LLB with $\lambda=0.83 \AA$, installed at the hot source of the ORPHEE reactor.

\begin{tabular}{lcccll}
\hline Atom & $x$ & $y$ & $z$ & occupancy & $U\left(\AA^{2}\right)$ \\
\hline \hline $\mathrm{Sr}$ & 0 & 0 & 0 & 1.00 & $U_{\text {iso }}=0.0310(17)$ \\
$\mathrm{Sc}$ & $1 / 2$ & $1 / 2$ & $1 / 2$ & $0.521(41)$ & $U_{\text {iso }}=0.0312(13)$ \\
$\mathrm{Ga}$ & $1 / 2$ & $1 / 2$ & $1 / 2$ & $0.479(41)$ & $U_{\text {iso }}=0.0312(13)$ \\
& & & & & $U_{11}=0.0390(32)$ \\
$\mathrm{O}$ & 0 & $1 / 2$ & $1 / 2$ & $2.462(42)$ & $U_{22}=U_{33}=0.0901(48)$
\end{tabular}

Refinements were carried out in space group $P m-3 m$ with unit cell parameter $a=3.9932 \AA$ (determined from XRPD, $\left.\mathrm{CuK}_{\alpha 1}\right) .152$ measured reflections $\left(\sin \theta / \lambda=0.72 \AA^{-1}\right)$, (49 unique) $\mathrm{R}_{\text {int }}(\mathrm{hkl})=3.1 \%, \mathrm{Rw}=10 \%$, GooF $=1.23$ 

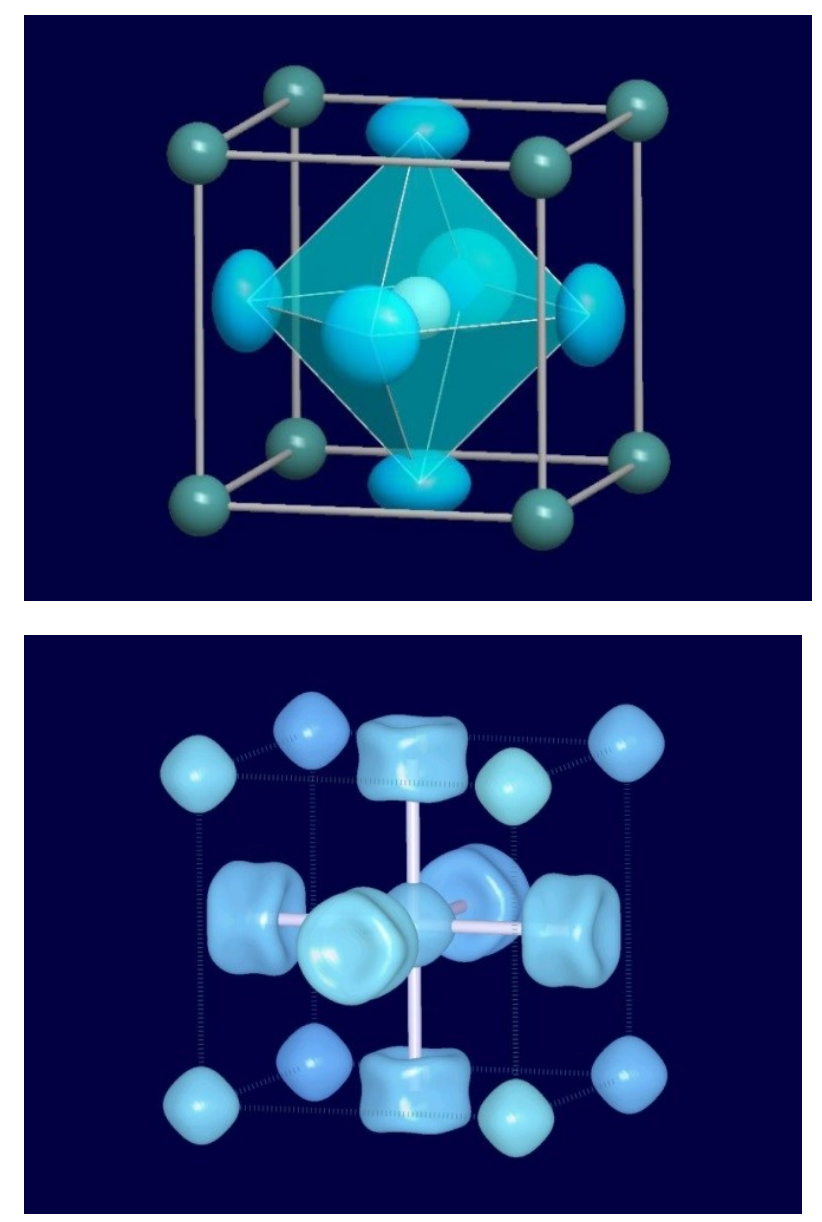

Figure 4: $(\mathrm{Sc} / \mathrm{Ga}) \mathrm{O}_{\mathrm{x}}$ polyhedra in c-SSGO, obtained at RT from neutron single crystal diffraction as harmonic description of the displacement factors (on the top) and the reconstructed nuclear scattering density using the Maximum Entropy Method (on the bottom). The perovskite unit cell 
and the $(\mathrm{Sc} / \mathrm{Ga}) \mathrm{O}_{6}$ octahedra are outlined. While isotropic displacements are found for $\mathrm{Sr}$ and $(\mathrm{Sc} / \mathrm{Ga})$, the iso-surfaces of oxygen atoms reveal an anisotropic cylindrical shape with significant deepening.

\section{Raman spectroscopy}

For an ideal cubic perovskite with $\mathrm{Pm}-3 \mathrm{~m}$ space group, no first-order Raman-active vibration frequencies are allowed. As shown in Figure 5, two relatively intense but broad peaks, centred at 600 and $743 \mathrm{~cm}^{-1}$ are nevertheless observed for c-SSGO. Their appearance is a consequence of the oxygen vacancies, and the related deviation from a local cubic symmetry ${ }^{29}$ Similar features have also been found in the proton conducting cubic perovskite $\mathrm{BaIn}_{\mathrm{x}} \mathrm{Zr}_{1-\mathrm{x}} \mathrm{O}_{3-\mathrm{x} / 2 .}{ }^{30}$ The two welldistinguished peaks correspond to the $(\mathrm{Sc} / \mathrm{Ga})-\mathrm{O}$ stretching modes ${ }^{30,31}$ and reinforce the hypothesis that in a first approach two distinct polyhedra, i.e. $\mathrm{GaO}_{4}$ tetrahedra and $\mathrm{ScO}_{6}$ octahedra, are present in c-SSGO 


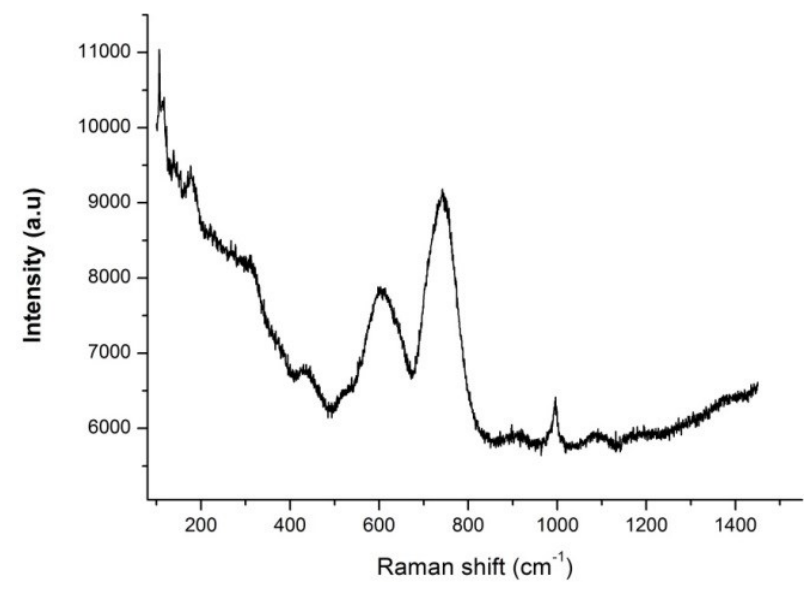

Figure 5: Raman spectrum of cubic oxygen deficient $\mathrm{Sr}_{2} \mathrm{ScGaO}_{5}$ with Perovskite structure, showing two separate peaks around 600 and $750 \mathrm{~cm}^{-1}$, associated to the stretching modes of $\mathrm{ScO}_{6}$ octahedra and $\mathrm{GaO}_{4}$ tetrahedra

\section{Impedance spectroscopy}

In order to directly access oxygen ion mobility, AC impedance measurements have been performed on the as grown single crystals up to $600^{\circ} \mathrm{C}$ along the [110] direction, corresponding to the crystal growth direction, as identified by Laue backscattering (see S2 supplementary info).

As expected from a single crystal study, the complex impedance spectrum of c-SSGO consists of single broad semi-circles (Figure 6) for all temperatures. Because the data were obtained on a single crystal, with a semicircle passing through the origin, they can be attributed to a bulk phenomenon and not to grain boundaries. The associated capacitance of about $6 \mathrm{pF}$ has been calculated using the usual relationship $\omega \mathrm{RC}=1$ at the top of each arc for all investigated 
temperatures. ${ }^{32}$ The bulk resistivity was modelled with an equivalent circuit made of a resistor (R) in parallel with a constant phase element (CPE). A second resistor $(\mathrm{R} \Omega)$ was added in series to model ohmic losses originating from the setup. Figure 7 shows the Arrhenius plot of the bulk conductivity data as resulting from the $\mathrm{AC}$ impedance measurements reported in Figure 6. The values are similar to those reported of the oxygen ionic conductor brownmillerite $\mathrm{Ba}_{2} \operatorname{In}_{2} \mathrm{O}_{5}{ }^{14}$ and of its cubic perovskite modification ${ }^{33}$ in the corresponding temperature range. The activation energy for c-SSGO single crystal of $0.67 \mathrm{eV}$ has been determined by a linear regression of the conductivity data. This value is, however, significantly lower compared to $1.34 \mathrm{eV}$, obtained for polycrystalline $\mathrm{Sr}_{2} \mathrm{Ga}_{1.5} \mathrm{Sc}_{0.5} \mathrm{O}_{5}{ }^{15}$, showing the same oxygen deficient cubic perovskite structure. This important difference is not supposed to be related to the change of the B-site cation stoichiometry and it cannot even be attributed to any proton mobility, as the absence of water was prior confirmed for the single crystal. Hence, we attribute the lower activation energy of cSSGO to the absence of grain boundaries compared to the polycrystalline SSGO sample reported in ${ }^{15}$. The availability of single crystalline electrodes for moderate temperature oxygen ion conductivity thus becomes important especially for this lower temperature range.

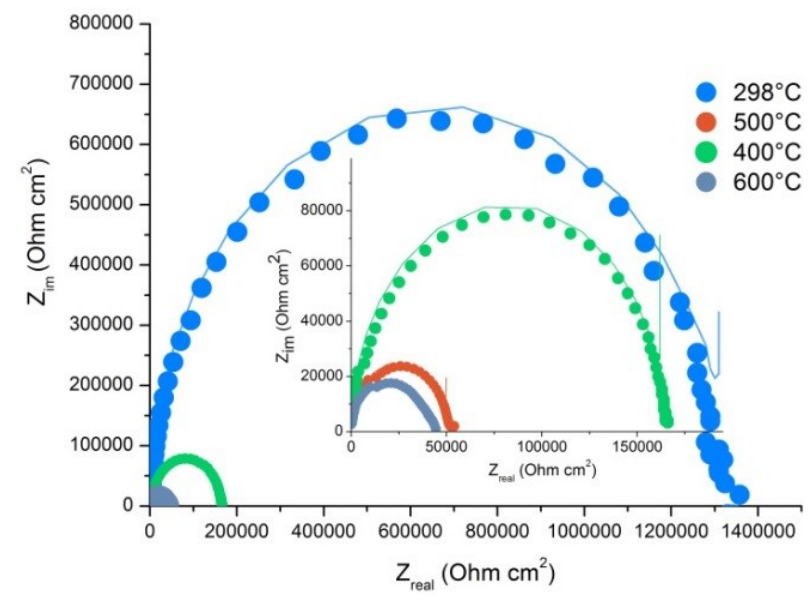


Figure 6: Cole-Cole plot obtained from AC impedance measurements on a c-SSGO single crystal at different temperatures. The inset shows a zoom for the values obtained at higher temperatures.

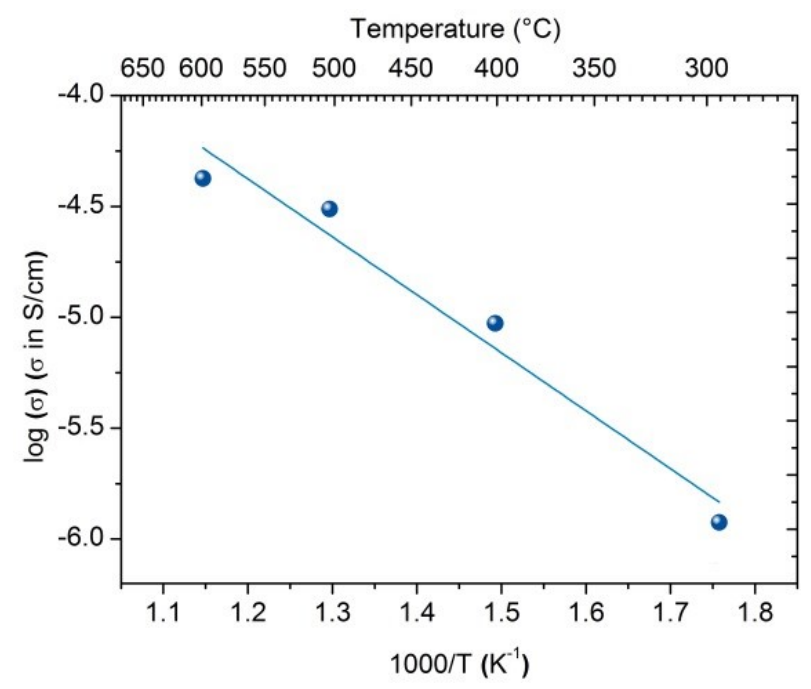

Figure 7: Temperature dependent Arrhenius plot of the bulk conductivity as obtained from the AC impedance measurements on the c-SSGO single crystal.

\section{Oxygen ${ }^{18} \mathrm{O} /{ }^{16} \mathrm{O}$ isotope exchange studies}

In order to investigate the temperature at which oxygen mobility appears, we performed TG experiments on polycrystalline ${ }^{18} \mathrm{O}$ enriched c-SSGO. Experiments were carried out in an atmosphere consisting of $\mathrm{O}_{2}(20 \%) / \mathrm{He}(80 \%)$, equivalent to the oxygen partial pressure in air. The onset temperature for "free" oxygen mobility is then given by the weight change associated to the ${ }^{18} \mathrm{O}$ vs. ${ }^{16} \mathrm{O}$ exchange. For a $100 \%$ enriched ${ }^{18} \mathrm{O}$ sample the corresponding mass change theoretically yields $2.65 \%$. 
Figure 8 shows the result of a TGA coupled MS study of c-SSG ${ }^{18} \mathrm{O}$, enriched by ${ }^{18} \mathrm{O}$ fairly close to $100 \%$, obtained with a heating rate of $5 \mathrm{~K} / \mathrm{min}$ up to $850^{\circ} \mathrm{C}$. The temperature was held for $3 \mathrm{~h}$ at $850^{\circ}$, before cooling down to ambient temperature again at $5 \mathrm{~K} / \mathrm{min}$. The detection of ${ }^{18} \mathrm{O}-{ }^{16} \mathrm{O}$ and pure ${ }^{18} \mathrm{O}_{2}$ molecules was simultaneously analyzed by mass spectroscopy. The TG signal reveals a mass reduction, starting above $500^{\circ} \mathrm{C}$, which is going along with the ${ }^{18} \mathrm{O} /{ }^{16} \mathrm{O}$ isotope exchange. Due to slow exchange kinetics even at quite elevated temperatures, complete exchange is only observed at the end of the plateau at $850^{\circ} \mathrm{C}$, corresponding to almost the theoretical mass loss of $2.60 \%$. This result is quite similar to what had been obtained on polycrystalline o-SSGO ${ }^{16}$ with Brownmillerite-type structure. These results imply on an absolute temperature scale a fairly low onset temperature for free oxygen diffusion, especially when considering SSGO as a pure oxygen electrolyte. The relatively low exchange kinetics indicated by ${ }^{18} \mathrm{O} /{ }^{16} \mathrm{O}$ isotope exchange underpins again the hypothesis that on a local level the cubic perovskite SSGO phase might consist of brownmillerite-type micro domains with 1D oxygen diffusion pathways, even though it appears overall cubic as resulting from diffraction studies.

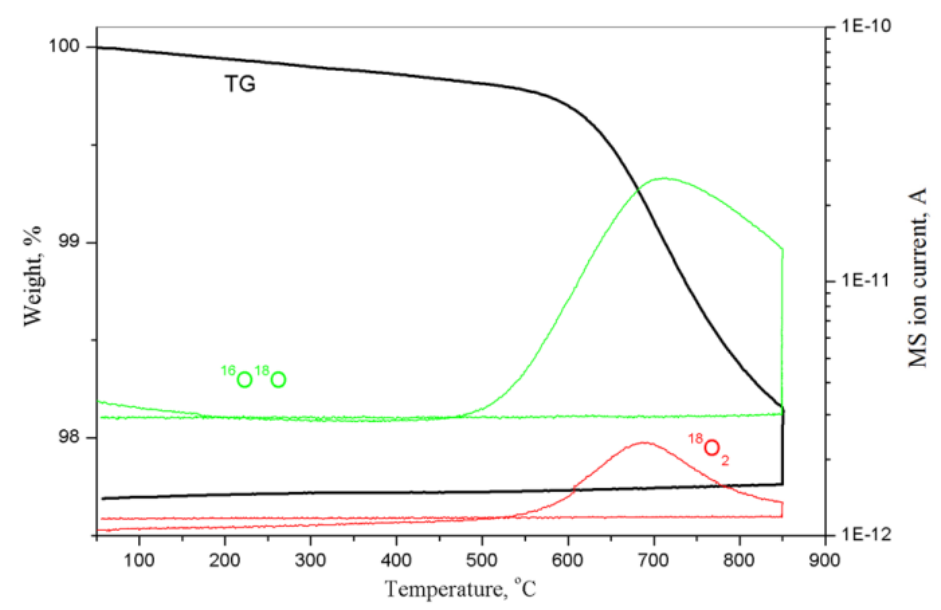

Figure 8: The TGA-MS spectroscopic study on $\mathrm{Sr}_{2} \mathrm{ScGa}^{18} \mathrm{O}_{5}$, enriched to above $90 \%$ of ${ }^{18} \mathrm{O}$. The experiment was performed in a ${ }^{16} \mathrm{O}_{2}(20 \%) / \mathrm{He}(80 \%)$ atmosphere with a heating rate of $5 \mathrm{~K}$. The 
decrease mass observed is $2.65 \%$. The decrease in mass (black line) sets in above $500^{\circ} \mathrm{C}$. The red and the green lines correspond to the intensities of the ${ }^{18} \mathrm{O}-{ }^{18} \mathrm{O}$ and ${ }^{18} \mathrm{O}-{ }^{16} \mathrm{O}$ mass signal respectively.

\section{Conclusions}

The structure and stability range of cubic $\mathrm{Sr}_{2} \mathrm{ScGaO}_{5}$ has been investigated by neutron and X-ray diffraction studies. While forming only above $1500^{\circ} \mathrm{C}$, it remains kinetically stabilized during furnace cooling down to ambient temperature. This allows growing high quality large single crystals $\mathrm{Sr}_{2} \mathrm{ScGaO}_{5}$ with an oxygen deficient perovskite structure, suitable for neutron structure investigations. The oxygen displacement factors reveal strong anisotropic cylindrical shape behaviour, as analysed by Maximum Entropy analysis. This suggests significant deviations of the oxygen atoms from their equilibrium positions in the perovskite framework. For oxygen deficient perovskites containing protonic defects, the proton position should consequently be considered to be localized significantly far away from the ideal oxygen positions, which is interesting as input parameter for simulations. From Raman spectroscopic studies the presence of two distinct peaks in the typical regions of M-O stretching modes, supports the formation of well-defined $\mathrm{GaO}_{4}$ and $\mathrm{ScO}_{6}$ polyhedra, and consequently the probable formation of brownmillerite-type micro domains within the cubic symmetry. It becomes thus clear that $\mathrm{Sr}_{2} \mathrm{ScGaO}_{5}$ is by far not comparable to the idealized perovskite framework, but shows an anionic sub-lattice with a complex modulation of the oxygen positions. We could importantly show that the activation energy of $0.67 \mathrm{eV}$ for the cubic $\mathrm{Sr}_{2} \mathrm{ScGaO}_{5}$ single crystal is only half the value as 
reported for polycrystalline $\mathrm{Sr}_{2} \mathrm{Ga}_{1.5} \mathrm{Sc}_{0.5} \mathrm{O}_{5}$, showing the same oxygen defect perovskite structure. This becomes specifically important at lower temperatures and underlines the interest of single crystalline electrodes, e.g. in form of epitaxial thin films, for oxygen ion conductivity at moderate temperatures.

\section{ASSOCIATED CONTENT}

\section{Supporting Information.}

The following files are available free of charge.

Crystal growth details, single crystal characterisation (neutron rocking curves, chemical composition, Laue pattern), and Neutron Powder Diffraction patterns as a function of the temperature (PDF)

\section{AUTHOR INFORMATION}

\section{Corresponding Author}

* Corresponding author: monica.ceretti@umontpellier.fr

\section{Author Contributions}

The manuscript was written through contributions of all authors. All authors have given approval to the final version of the manuscript.

\section{Funding Sources}


This work was partially financially supported by the French National Research Agency, through the project AMOXIS (No. ANR-14-CE05-0016-02).

\section{ACKNOWLEDGMENT}

We are grateful to Dr. B. Fraisse and Dr. D. Bourgogne of the "Plateforme d'Analyse et de Caractérisation du Pôle Chimie Balard", Montpellier (France), for X-rays thermodiffraction measurements and Raman measurements. We would like to thank the Laboratoire Léon Brillouin (LLB, Saclay, France) and the Institut Laue Langevin (ILL Grenoble, France) for the allocation of the neutron beam time. We acknowledge Prof. K. Conder, PSI-Villigen (Switzerland), for TGA measurements.

\section{REFERENCES}

1. $\quad$ Skinner, S. J.; Kilner, J. A. Oxygen ion conductors. Materials Today 2003, 6 (3), 30-37 DOI: http://dx.doi.org/10.1016/S1369-7021(03)00332-8.

2. $\quad$ Marques, F. M. B.; Kharton, V. V.; Naumovich, E. N.; Shaula, A. L.; Kovalevsky, A. V.; Yaremchenko, A. A. Oxygen ion conductors for fuel cells and membranes: selected developments. Solid State Ionics 2006, 177 (19-25), 1697-1703 DOI: http://dx.doi.org/10.1016/j.ssi.2006.04.036. 3. Ishihara, T.; Matsuda, H.; Takita, Y. Doped LaGaO3 Perovskite Type Oxide as a New Oxide Ionic Conductor. Journal of the American Chemical Society 1994, 116 (9), 3801-3803 DOI: 10.1021/ja00088a016. 
4. Goodenough, J. B.; Manthiram, A.; Kuo, J. F. Oxygen diffusion in perovskite-related oxides. Materials Chemistry and Physics 1993, 35 (3), 221-224 DOI: http://dx.doi.org/10.1016/0254-0584(93)90135-9.

5. Steele, B. C. H.; Heinzel, A. Materials for fuel-cell technologies. Nature 2001, 414 (6861), 345-352.

6. Tao, S. W.; Irvine, J. T. S.; Kilner, J. A. An Efficient Solid Oxide Fuel Cell Based upon Single-Phase Perovskites. Advanced Materials 2005, 17 (14), 1734-1737 DOI: 10.1002/adma.200402007.

7. Jacobson, A. J. Materials for Solid Oxide Fuel Cells. Chemistry of Materials 2010, 22 (3), 660-674 DOI: $10.1021 / \mathrm{cm} 902640 \mathrm{j}$.

8. $\quad$ Hibino, M.; Harimoto, R.; Ogasawara, Y.; Kido, R.; Sugahara, A.; Kudo, T.; Tochigo, E.; Shibata, N.; Ikuhara, Y.; Mizuno, N. A New Rechargeable Sodium Battery Utilizing Reversible Topotactic Oxygen Extraction/Insertion of $\mathrm{CaFeOz}(2.5<=\mathrm{z}<=3)$ in an Organic Electrolyte. Journal of the American Chemical Society 2014, 136 (1), 488-494 DOI: 10.1021/ja411365z.

9. Ichikawa, N.; Iwanowska, M.; Kawai, M.; Calers, C.; Paulus, W.; Shimakawa, Y. Reduction and oxidation of $\mathrm{SrCoO} 2.5$ thin films at low temperatures. Dalton Transactions 2012, 41 (35), 10507-10510 DOI: 10.1039/C2DT30317E

10. Jeen, H.; Choi, W. S.; Biegalski, M. D.; Folkman, C. M.; Tung, I. C.; Fong, D. D.; Freeland, J. W.; Shin, D.; Ohta, H.; Chisholm, M. F.; Lee, H. N. Reversible redox reactions in an epitaxially stabilized SrCoOx oxygen sponge. Nature Materials 2013, 12 (11), 1057-1063 DOI: 10.1038/nmat3736.

11. Le Toquin, R.; Paulus, W.; Cousson, A.; Prestipino, C.; Lamberti, C. Time-resolved in situ studies of oxygen intercalation into $\mathrm{SrCoO} 2.5$, performed by neutron diffraction and X-ray absorption spectroscopy. Journal of the American Chemical Society 2006, 128 (40), 13161-13174 DOI: $10.1021 / \mathrm{ja} 063207 \mathrm{~m}$.

12. Nemudry, A.; Weiss, P.; Gainutdinov, I.; Boldyrev, V.; Schollhorn, R. Room temperature electrochemical redox reactions of the defect perovskite $\mathrm{SrFeO} 2.5+\mathrm{x}$. Chemistry of Materials 1998, 10 (9), 2403-2411 DOI: 10.1021/cm980090v.

13. Paulus, W.; Schober, H.; Eibl, S.; Johnson, M.; Berthier, T.; Hernandez, O.; Ceretti, M.; Plazanet, M.; Conder, K.; Lamberti, C. Lattice Dynamics To Trigger Low Temperature Oxygen Mobility in Solid Oxide Ion Conductors. Journal of the American Chemical Society 2008, 130 (47), 16080-16085 DOI: 10.1021/ja806144a.

14. Goodenough, J. B.; Ruiz-Diaz, J. E.; Zhen, Y. S. Oxide-ion conduction in Ba2In2O5 and Ba3In2MO8 $(\mathrm{M}=\mathrm{Ce}, \mathrm{Hf}, \quad$ or $\mathrm{Zr})$. Solid State Ionics 1990, 44 (1), 21-31 DOI: http://dx.doi.org/10.1016/0167-2738(90)90039-T.

15. Chernov, S. V.; Dobrovolsky, Y. A.; Istomin, S. Y.; Antipov, E. V.; Grins, J.; Svensson, G.; Tarakina, N. V.; Abakumov, A. M.; Van Tendeloo, G.; Eriksson, S. G.; Rahman, S. M. H. $\mathrm{Sr} 2 \mathrm{GaScO} 5, \mathrm{Sr} 10 \mathrm{Ga} 6 \mathrm{Sc} 4 \mathrm{O} 25$, and $\mathrm{SrGa} 0.75 \mathrm{Sc} 0.25 \mathrm{O} 2.5$ : a Play in the Octahedra to Tetrahedra Ratio in Oxygen-Deficient Perovskites. Inorganic Chemistry 2012, 51 (2), 1094-1103 DOI: 10.1021/ic202236h.

16. Corallini, S.; Ceretti, M.; Silly, G.; Piovano, A.; Singh, S.; Stern, J.; Ritter, C.; Ren, J.; Eckert, H.; Conder, K.; Chen, W.-t.; Chou, F.-C.; Ichikawa, N.; Shimakawa, Y.; Paulus, W. OneDimensional Oxygen Diffusion Mechanism in Sr2ScGaO5 Electrolyte Explored by Neutron and Synchrotron Diffraction, 17O NMR, and Density Functional Theory Calculations. The Journal of Physical Chemistry C 2015, DOI: 10.1021/acs.jpcc.5b02173. 
17. Ceretti, M.; Corallini, S.; Paulus, W. Influence of Phase Transformations on Crystal Growth of Stoichiometric Brownmillerite Oxides: Sr2ScGaO5 and Ca2Fe2O5. Crystals 2016, 6 (11), 146.

18. Sheldrick, G. A short history of SHELX. Acta Crystallographica Section A 2008, 64 (1), 112-122 DOI: doi:10.1107/S0108767307043930.

19. Rietveld, H. M. Line Profile of neutron powder diffraction peaks for structure refinement. Acta Crystallographica 1967, 22, 151-155 DOI: 10.1107/s0365110x67000234.

20. Frontera, C.; Rodriguez-Carvajal, J. FULLPROF as a new tool for flipping ratio analysis. Physica B-Condensed Matter 2003, 335 (1-4), 219-222 DOI: 10.1016/s0921-4526(03)00241-2.

21. F. Izumi , R. A. D. Recent Research Developments in Physics; 81-7895-046-4; 2002; pp 699-726.

22. Koester, L. In Neutron Physics; Springer Berlin Heidelberg: 1977; Chapter 1, Vol. 80, pp $1-55$.

23. Momma, K.; Izumi, F. VESTA 3 for three-dimensional visualization of crystal, volumetric and morphology data. Journal of Applied Crystallography 2011, 44 (6), 1272-1276 DOI: doi:10.1107/S0021889811038970.

24. Rodríguez-Carvajal, J. Recent developments of the program FullProf. Commission for Powder Diffraction. IUCr Newsletter 2001, 26, 12-19. The complete FULLPROF suite can be obtained from: http://www.ill.eu/sites/fullprof/index.html.

25. Lindberg, F.; Svensson, G.; Istomin, S. Y.; Aleshinskaya, S. V.; Antipov, E. V. Synthesis and structural studies of $\mathrm{Sr} 2 \mathrm{Co} 2-\mathrm{xAlxO}, 0.3 \leqslant \mathrm{x} \leqslant 0.5$. Journal of Solid State Chemistry 2004, 177 (4-5), 1592-1597 DOI: http://dx.doi.org/10.1016/j.jssc.2003.12.012.

26. Gallagher, P. K.; MacChesney, J. B.; Buchanan, D. N. E. Mössbauer Effect in the System SrFeO2.5-3.0. The Journal of Chemical Physics 1964, 41 (8), 2429-2434 DOI: doi:http://dx.doi.org/10.1063/1.1726282.

27. Berastegui, P.; Hull, S.; García-García, F. J.; Eriksson, S. G. J. Solid State Chem. 2002, $164,119$.

28. Ahmed, I.; Knee, C. S.; Karlsson, M.; Eriksson, S. G.; Henry, P. F.; Matic, A.; Engberg, D.; Börjesson, L. J. Alloys Compd. 2008, 450, 103.

29. Siny, I. G.; Katiyar, R. S.; Bhalla, A. S. Cation arrangement in the complex perovskites and vibrational spectra. Journal of Raman Spectroscopy 1998, 29 (5), 385-390 DOI: 10.1002/(sici)1097-4555(199805)29:5<385::aid-jrs250>3.0.co;2-f.

30. Karlsson, M.; Matic, A.; Knee, C. S.; Ahmed, I.; Eriksson, S. G.; Börjesson, L. ShortRange Structure of Proton-Conducting Perovskite BaInxZr1-xO3-x/2 $(\mathrm{x}=0-0.75)$. Chemistry of Materials 2008, 20 (10), 3480-3486 DOI: 10.1021/cm7025448.

31. Bielecki, J.; Parker, S. F.; Ekanayake, D.; Rahman, S. M. H.; Borjesson, L.; Karlsson, M. Short-range structure of the brownmillerite-type oxide Ba2In2O5 and its hydrated protonconducting form BaInO3H. Journal of Materials Chemistry A 2014, 2 (40), 16915-16924 DOI: 10.1039/c4ta03213f.

32. Bauerle, J. E. Study of solid electrolyte polarization by a complex admittance method. Journal of Physics and Chemistry of Solids 1969, 30 (12), 2657-2670 DOI: http://dx.doi.org/10.1016/0022-3697(69)90039-0.

33. Yamamura, H.; Hamazati, H.; Kakinumai, K.; MOori, T.; Haneda, H. Order-disorder transition and Electrical Conductivity of the brownmillerite solid solutions System Ba2(In,M)2O5 (M=Ga,Al). Journal of Korean Physical Society 1999, 35, S200-S204. 


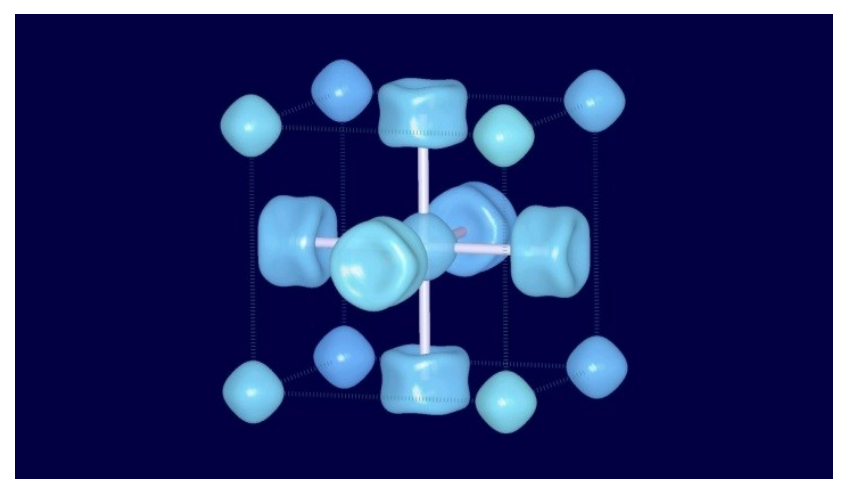

For Table of Contents Only

Anharmonic oxygen thermal displacement parameters, explored by high resolution single crystal neutron scattering coupled with Maximum Entropy reconstruction, in the $\mathrm{Sr}_{2} \mathrm{ScGaO}_{5}$ oxygen deficient cubic perovskite. 